\title{
A Forecast Model of Agricultural and Livestock Products Price
}

\author{
Wensheng Zhang ${ }^{1, *}$, Hongfu Chen ${ }^{1}$, and Mingsheng Wang ${ }^{2}$ \\ ${ }^{1}$ College of Civil Engineering, Shijiazhuang Railway Institute, Shijiazhuang, Hebei, \\ China 050043, \\ Tel.: +86311-87939151 \\ xyns@hotmail.com \\ ${ }^{2}$ College of Traffic Engineering, Shijiazhuang Railway Institute, Shijiazhuang, Hebei, \\ China 050043
}

\begin{abstract}
The frequent and excessive fluctuation of agricultural and livestock products price is not only harmful to residents' living, but also affects CPI (Consumer Price Index) values, and even leads to social crisis, which influences social stability. Therefore it is important to forecast the price of agriculture and livestock products. As a result, we make a research on the factors affecting agricultural and livestock products price, establish a forecasted model of agricultural and livestock products price, and develop its early-warning system which is suitable to China. Considering the direct relationship between the price and the output, multiple linear regression method is adopted to study this problem. The model is composed of three sub-models. This paper puts forward the concept of price equilibrium coefficient $\mathrm{C}_{0}$, which describes the degree to which people accepting the forecasted price. With the establishment of the standard for the influence of price fluctuation, the influence of price fluctuation is measured. Each range of the $\mathrm{C}_{0}$ value corresponds with a specific result, which may informs the government with the danger of price fluctuation. As a result, the model can early-warn the price rising caused by crop reduction due to sudden natural disaster, which may induce social turmoil and crisis. If the forecasted price rises heavily, the government should take measures to avoid crisis. This paper offers the method to control future price. At last, a forecasted model of pork price is calculated with simulated data. The forecasted result is in good agreement with actual situation.
\end{abstract}

Keywords: multiple linear regression, forecast model, price equilibrium coefficient, RS, GIS.

\section{Introduction}

Agricultural and livestock products are closely related with residents' life, and the stability of products' price is important to social stability. In 2008, the reduction of rice in the world's major grain-producing countries led to sharp drop in their exports

\footnotetext{
${ }^{*}$ Corresponding author.
} 
of agricultural products, which resulted in skyrocketing food prices, violence and even bloodshed in some areas of food-importing countries. From January to October in 2007, some cities in southern China saw pig fever, which led to less pigs farrowed, high mortality and sharp reduction of pig population. Pig population reduction triggered rising meat price at 22-26 Yuan per kilogram in October, which then quickly spread nationwide. Many ordinary Chinese residents missed a meal of pork and complained a lot. Rising price of agricultural products promotes the CPI to a large degree. The National Bureau of Statistics CPI data showed that in February 2008 CPI rose by $8.7 \%$ over the same period last year, and rose by 2.6 percent at ring growth. Among them, food prices rose by $23.3 \%$, non-food prices rose by $1.6 \%$. The above information shows the inadequate preparation for agricultural and livestock price rise led to a crisis.

Markov Chain and multistage fuzzy comprehensive estimation are applied in forecasting of the agro-products price (Yu pingfu, 2005). Time serial model is used to forecast pork price in Henan Province, China (Sheng Jianhua, et al., 2008).

At present, the forecast method for the price of agricultural and livestock products mainly based on the past products price and work experience, which can't forecast products price accurately and timely in some situation. Therefore, it is necessary to propose the agricultural and livestock products price prediction model in case of emergent agriculture, animal and husbandry disaster, so that decision-making department can foretell and adopt a positive response.

\section{To Monitor and Analyze the Information of Agricultural Products Growth Based on RS and GIS}

By using the correct high-resolution MODIS remote sensing images and professional remote sensing analysis software Erdas Imagine we can analyze the related information of farming land, such as the health state of growth, crop acreage etc. Establishing geographic information systems of the prices of agricultural products based on Map X 5.0, we can make analysis in the system and produce thematic price maps of agricultural products, measure the volume of growth area of local crops, and achieve database connection.

\section{The Forecast Model of Agricultural and Livestock Products Price}

In fact, a phenomenon is often associated with a number of factors, and it is more effective and realistic to predict or estimate a common dependent variable by a number of the optimal combination of independent variables rather than just one variable. In the regression analysis, if there are two or more independent variables, and each independent variable and dependent variable only has linear relationship, it is known as multiple linear regression. The prices of agricultural products are affected by many factors. Interactions between various factors are interrelated. Thus, the prediction method applies multiple linear regression method. Through the establishment of multi-linear equations for each of the influential factors as 
explanatory variables, forecast prices will be interpreted as a variable. Model is structured as follows:

$$
Y=\beta_{1}+\beta_{2} X_{1}+\cdots+\beta_{k} X_{k}
$$

When prices of agricultural products are forecasted, the characteristics of various influential factors are taken into full account. The influential factors are divided into two categories: external factors and internal factors. External factors refer to the external environmental factors, such as population, transportation conditions and other factors. Internal factors refer to the reasons of agricultural products, such as agricultural yield and other factors. External factors and internal factors have different influences on the prices of agricultural products. Therefore, we use internal factors and external factors respectively to predict the prices of agricultural products. Finally, using the weighted method to integrate their predictive equation into the recent agricultural prices, the agricultural price prediction equation will be achieved. All the coefficient data of predictive equation will be integrated into equation set based on the recent data, and corresponding coefficient is achieved.

\subsection{The Establishment of the Model}

\section{(1) Model I}

Analysis the external factors that impact the prices of agricultural products. A number of these factors are used as explanatory variables, and forecasted prices will be interpreted as variables, price forecasts multivariate linear regression equation is constructed.

$$
Y_{1}=Q_{1}+Q_{2} X_{1}+\cdots+Q_{i} X_{i}
$$

Where: $Q_{1}, Q_{2}$ and $Q_{i}$ are the coefficients of the forecasting formula, $X_{1}$ and $X_{i}$ are the external factors, $\mathrm{Y}_{1}$ is the forecasting price of agricultural and livestock's products by external factors.

(2) Model II

Analysis the internal factors that impact the prices of agricultural products.

A number of these factors are used as explanatory variables, and forecasted prices will be interpreted as variables, price forecast multivariate linear regression equation is constructed.

$$
Y_{2}=P_{1}+P_{2} X_{i+1}+\cdots+P_{j} X_{j}
$$

Where: $\mathrm{P}_{1}, \mathrm{P}_{2}$ and $\mathrm{P}_{\mathrm{i}}$ are the coefficients of the forecasting formula, $\mathrm{X}_{\mathrm{i}+1}$ and $\mathrm{X}_{\mathrm{j}}$ are the internal factors, $\mathrm{Y}_{2}$ is the forecasting price of agricultural and livestock's products by internal factors.

(3) Model III

The factors of recent price of agricultural products are added to external factor prediction model as explanatory variables, and forecasted prices will be interpreted as variables, price forecast multivariate linear regression equation is constructed.

$$
Y_{3}=M_{1}+M_{2} X_{1}+\cdots+M_{i} X_{i}+M_{j+1} X_{j+1}
$$


Where: $\mathrm{M}_{1}, \mathrm{M}_{2}, \mathrm{M}_{3}$ and $\mathrm{M}_{\mathrm{j}+1}$ are the coefficients of the forecasting formula, $\mathrm{X}_{\mathrm{j}+1}$ is recent price of agricultural and livestock's products, $\mathrm{Y}_{3}$ is the forecasting price of agricultural and livestock's products.

(4) Model IV

Based on the above three model structure, using the weighted method, the integrated prediction model is formed.

$$
\begin{gathered}
Y=K_{1}\left(Q_{1}+Q_{2} X_{1}+\cdots+Q_{i} X_{i}\right)+K_{2}\left(P_{1}+P_{2} X_{i+1}+\cdots+P_{j} X_{j}\right) \\
K_{3}\left(M_{1}+M_{2} X_{1}+\cdots+M_{i} X_{i}+M_{j+1} X_{j+1}\right)
\end{gathered}
$$

Where: $\mathrm{Y}$ is the finally forecasting price, $\mathrm{K}_{1}, \mathrm{~K}_{2}$, and $\mathrm{K}_{3}$ are the coefficients of each model. $\mathrm{K}_{1}+\mathrm{K}_{2}+\mathrm{K}_{3}=1$. The selection of $\mathrm{K}$ value can be flexible according to the actual situation, focusing on the factors that need to be expressed.

In order to increase the accuracy of the forecasting result, we suggest the value of $\mathrm{K}_{3}$ should be great than 0.33 .

\subsubsection{Model Applicability}

The model can be applied to some local areas such as counties and townships, but also can be applied to other large areas such as big cities. As to agricultural products with a longer growth cycle and deeper influence, it can be forecasted within large areas (with province as a unit), which has great practical significance. Forecast time can have weeks, months, and years so on as units. Of course there is no practical significance if the forecasting time span is too short or too long. In addition, before the forecast, it is needed to determine the coefficients of the model structure based on the actual data.

\subsection{Price Equilibrium Coefficient}

In order to evaluate the prices of agricultural products, the concept of price equilibrium coefficient is proposed. The concept of price equilibrium coefficient $\mathrm{C}_{0}$ refers to the extent of the prices of agricultural products that are acceptable to the residents. It is expressed through dividing the remainder of forecasted price subtracted by the pre-agricultural prices by the percentage of pre-agricultural prices expressed in absolute terms. The formula is as follows:

$$
\begin{gathered}
C_{0}=\left|\frac{Y-P_{1}}{P_{1}} \times 100 \%\right| \\
C_{0}=\left|\frac{Y-P_{1}^{*}\left(1-3^{*} C\right)}{P_{1}^{*}(1-3 * C)} \times 100 \%\right|
\end{gathered}
$$

Where: $\mathrm{Y}$ is the forecasting price of the agricultural and livestock's products, $\mathrm{P}_{1}$ is the recent price of the agricultural and livestock's products, $\mathrm{C}$ is current coefficient of CPI.

(1) When $\mathrm{CPI}<3 \%$, formula (1-5) is applied.

(2) When CPI $>3 \%$, formula (1-6) is applied. 


\subsubsection{The Significance of $\mathbf{C}_{0}$}

According to large amounts of data I have read and my actual analysis, the significance of the actual values of $\mathrm{C}_{0}$ is given, as shown in Table 1 .

Table 1. The range and significance of value of $C_{0}$

\begin{tabular}{cc}
\hline The range of value of $\mathrm{C}_{0}$ & The significance of value of $\mathrm{C}_{0}$ \\
\hline $0 \sim 8 \%$ & The price fluctuation is reasonable \\
$8 \sim 17 \%$ & The price fluctuation problem is minor \\
$17 \sim 30 \%$ & The price fluctuation problem is major \\
$30 \sim 55 \%$ & The price fluctuation problem is serious \\
More than $55 \%$ & The price fluctuation problem is \\
& amazingly serious \\
\hline
\end{tabular}

When confronted with the actual situation, for agricultural products are different from one another, the value of $\mathrm{C}_{0}$ is possibly different. If necessary, $\mathrm{C}_{0}$ can be multiplied by the values ranging between 0.2 and 0.7 , so that a more accurate price equilibrium exponent will be achieved.

\subsection{The Regulatory Function of the Forecast Model of Agricultural Products Price}

The government policy makers can make corresponding macro regulations based on evaluated value of price equilibrium coefficient and actual condition, so that the price equilibrium coefficient can return to safe scope. The steps are as follows:

(1) The reasonable price is got by abductive reasoning, based on reasonable price range of price equilibrium coefficient.

(2) Aided by integrated evaluation model, we can get the factor-adjustable quantum by analyzing easily adjusted factors and adjusting single factor.

(3) Re-predict the price of agricultural products and conduct price evaluation.

For instance: When prediction shows the price equilibrium exponent of marketable rice ranges from $17 \%$ to $30 \%$, the price fluctuation problem is comparatively serious over a period in the future, we can calculate the rice quantity we need to add to market by abductive reasoning, re-predict and evaluate the rice price based on reasonable price level and aided by integrated model structure.

\section{The Forecast Model of Pork Price}

From year 2008 to 2009, pork price in China had been fluctuated obviously. The pork price is not only related to the amount of pork production, but it is also affected by transport costs, population and economic ability, etc. Here we can apply the forecasting model of agricultural and livestock products price to forecast the pork price. 
In order to establish the model, we need to consider many factors which affect the pork price, such as the volume of pig slaughter, the volume of pig stock, transportation cost, local non-agricultural population, per capita GDP, the amount of per capita consumption on pork, food price for pigs, recent pork price and so on.

SPSS (Statistical Package for the Social Science) is one of well-known statistical analysis software packages for social sciences in the world. It can carry out multiple linear regression analysis. Applying SPSS software analysis, we can get the following models.

(1) Model I

This model reflects the relationship between pork price and external factors, such as non-agricultural population, GDP, amount of per capita consumption on pork and so on.

$$
Y_{1}=-0.11 X_{1}+0.068 X_{2}-0.02 X_{3}+9.174
$$

Where: $X_{1}$ is non-agricultural population in forecasted region (unit: 10,000 people), $\mathrm{X}_{2}$ is per-capita GDP (unit: 10,000 Yuan), $\mathrm{X}_{3}$ is the amount of per-capita consumption on pork (unit: Yuan).

(2) Model II

This model reflects the relationship between pork price and internal factors, which include the volume of pig stock, the volume of pig slaughter, food price for pigs and transportation cost.

$$
Y_{2}=-0.467 X_{4}-0.251 X_{5}+1.254 X_{6}+0.374 X_{7}+18.529
$$

Where: $\mathrm{X}_{4}$ is the volume of pig slaughter (unit: 10,000 pigs), $\mathrm{X}_{5}$ is the volume of pig stock (unit: 10,000 pigs), $X_{6}$ is the price of food for pigs per kilogram (unit: Yuan), $X_{7}$ is the cost of transportation per pig (unit: Yuan).

(3) Model III

By introducing the factor of recent pork price, then we got the following model III based on model I.

$$
Y_{3}=0.002 X_{1}-0.12 X_{3}+0.771 X_{8}+2.75
$$

Where: $\mathrm{X}_{8}$ is recent pork price per 500 grams (unit: Yuan).

(4) Integrated Model IV

Based on the above three models, we got the following integrated model IV.

$$
\begin{aligned}
& Y=K_{1} *\left(0.11 X_{1}+0.068 X_{2}-0.02 X_{3}+9.174\right)+K_{2} *\left(-0.467 X_{4}\right. \\
& \left.-0.251 X_{5}+1.254 X_{6}+0.374 X_{7}+18.529\right)+K_{3} *\left(0.002 X_{1}-0.12 X_{3}\right. \\
& \left.+0.771 X_{8}+2.75\right)
\end{aligned}
$$

According to the simulated data shown in Table 2, we can get the forecasting price which is 10.91 Yuan per 500 grams by the integrated model IV. Because C is less than $3 \%$, we can use formula 1-5 to calculate price equilibrium coefficient $\mathrm{C}_{0}$. As a result, the $\mathrm{C}_{0}$ value is $9.1 \%$, indicating the pork price fluctuation will cause a small problem in the next period in the city. If no measures are taken, price will increase, thus giving a fillip to CPI index. 
Table 2. Simulated Data used in Model

\begin{tabular}{clcc}
$\begin{array}{c}\text { Factor } \\
\text { Name }\end{array}$ & $\begin{array}{l}\text { Factor } \\
\text { Value }\end{array}$ & $\begin{array}{l}\text { Factor } \\
\text { Name }\end{array}$ & $\begin{array}{c}\text { Factor } \\
\text { Value }\end{array}$ \\
\hline $\begin{array}{c}\text { non-agricultural } \\
\text { population in city } \\
\text { present amount of } \\
\text { pig stock }\end{array}$ & $1,500,000$ & $\begin{array}{c}\text { price of food } \\
\text { for pigs }\end{array}$ & 2.5 Yuan $/ \mathrm{kg}$ \\
$\begin{array}{c}\text { present amount of } \\
\text { pig slaughter }\end{array}$ & 300,000 & transportation & 12 Yuan \\
current CPI value & 70,000 & cost & per pig \\
K2 & $2.5 \%$ & price & 10 Yuan \\
& 0.35 & K1 & per 500g \\
& & K3 & 0.25 \\
\hline
\end{tabular}

\subsection{The Regulation Function of the Forecast Model of Pork Price}

The factors which influence the price of pork are as follows: the volume of pig slaughter, the volume of pig stock, etc. The population of pigs and slaughtered ones are macro-controlled through comprehensive analysis of these adjustable factors.

(1) Through the abductive reasoning of formula $\mathrm{C}_{0}$, reasonable pork price is 10.8 Yuan per 500 grams.

(2) Based on formula 1-10, we calculate that 3000 slaughtered pigs need to be increased, and pig stock population increases by 8000 .

(3) The re-forecasted price is 10.79 Yuan per 500 grams, $\mathrm{C}_{0}$ exponent is $7.9 \%$, and the price is a reasonable price.

Through the forecast and adjustment process mentioned above, a potential crisis is resolved successfully. This not only provides convenience to the government, but also brings about tangible benefits to the residents.

\section{Conclusion and Discussions}

Through the study on the forecasting model of agricultural and livestock products price and its application in pork price with simulated data, we can get conclusions as follows:

(1) With multiple linear regression method we can predict pork price. The results in SPSS show that there is a high correlation between pork price and influential factors. Considering that agricultural and livestock products price is correlated with its own output, we can apply the present method to the price prediction of other products.

(2) The study on agricultural and livestock's products price fluctuation evaluation can evaluate the predicted price. According to the price fluctuation evaluation, the predicted products price can be evaluated so that price warning can be made. 
(3) The adjustment of agricultural and livestock products price can play a very important role in the government's management on agricultural and livestock products price. This paper provides the process how pork price is adjusted with the help of the model. The government can predict the time when the price would change and control its change by regulating its output or other related factors.

More practical experiments are needed to enhance the model's accuracy. In addition, the prediction model is set up based on the simulated data in Hebei province, China. For the sake of the model's wider application, the real data of related factors is needed when it is applied to predict agricultural and livestock products price in some specific areas.

\section{Acknowledgements}

Great thanks go to Professor Stefano Bocchi from the University of Milan for his guidance on research methods and ideas. Besides, thank a lot the Hebei Academy of Agriculture and Forestry Sciences for the help provided in the application.

\section{References}

Marion, B.W., Geithman, F.E.: Concentration-price relations in regional fed cattle markets. Review of Industrial Organization 10(1), 1-19 (1995)

Yue, E., Jianbing, Z., Yeping, Z., Kaimeng, S.: Agriculture economy information service system based on embedded GIS. Computer Engineering 34(23), 269-271 (2008) (in Chinese)

Kanis, E., Groen, A.F., De Greef, K.H.: Societal Concerns about Pork and Pork Production and Their Relationships to the Production System. Journal of Agricultural and Environmental Ethics 16(2), 137-162 (2003)

Ehui, S., Polson, R.: A review of the economic and ecological constraints on animal draft cultivation in sub-Saharan Africa. Soil Tillage Res. 27, 197-210 (1993)

Juan, G., Huimin, L.: An Analysis of the Trend of Impact of Agricultural Product Price Fluctuation in China. Social Science Journal of Shenyang Agricultural University 9(2), 144-147 (2007) (in Chinese)

Kiers, H.A.L., Smilde, A.K.: A comparison of various methods for multivariate regression with highly collinear variables. Statistical Methods and Applications 16(2), 193-228 (2007)

Apergis, N., Rezitis, A.: Mean spillover effects in agricultural prices: Evidence from changes in policy regimes. International Advances in Economic Research 9(1), 69-78 (2003)

Chunling, P.: Analysis and suggestion: thirty years of fluctuation and development of live-pig production of Liaoning province. Social Science Journal of Shenyang Agricultural University 10(6), 649-653 (2008) (in Chinese)

Chakrabarty, S., Chopin, M., Darrat, A.: Predicting Future Buyer Behavior with Consumers' Confidence and Sentiment Indexes. Marketing Letters 9(4), 349-360 (1998)

Jianhua, S., Gongpeng, C., Xixin, J., Guangzhi, R., Tengyun, G., Xiaofeng, L.: Study on the change rule and forecast of pork price in Henan Province. Journal of Henan Agricultural University 42(6), 672-676 (2008) (in Chinese)

Jagtap, S., Amissah-Arthur, A.: Stratification and synthesis of crop-livestock production system using GIS. GeoJournal 47, 573-582 (1999) 
Bocchi, S., Annamaria, Castrignanò: Identification of different potential production areas for corn in Italy through multitemporal yield map analysis. Field Crops Research 102(3), 185-197 (2007)

Pingfu, Y.: Study on the Construction and Application of Model Prediction System of the Agroproducts. Journal of Anhui Agricultural Sciences 33(7), 1284-1286 (2005) (in Chinese)

Zanias, G.P.: Inflation, Agricultural Prices and Economic Convergence in Greece. European Review of Agricultural Economics 25, 19-29 (1998) 